\title{
Accuracy of postmortem radiography of excised air-inflated human lungs in assessment of pulmonary emphysema
}

\author{
SEPPO SUTINEN, PENTTI LOHELA, PAAVO PÄÄKKÖ, REIJO LAHTI \\ From the Departments of Pathology and Diagnostic Radiology, University of Oulu, Oulu, Finland
}

ABSTRACT The accuracy of radiography of excised air-inflated lungs in assessing pulmonary $\vec{\nabla}$ emphysema at necropsy was evaluated in a series of 107 adults who had died in hospital by reading $\mathbb{D}$ the radiographs and examining the pathological specimens independently. The radiographic and $\stackrel{\oplus}{3}$ pathological assessments of the severity of emphysema correlated significantly $\left(r=0 \cdot 87,{ }_{0}^{\circ}\right.$ $\mathrm{p}<0.0001$ ). Mild emphysema was recognised radiographically in $88.7 \%$ and moderate in $94.9 \%$ of the lungs. One of 16 normal lungs $(6 \cdot 3 \%)$ was radiographically diagnosed as showing mild $\underset{\infty}{\mathscr{Q}}$ emphysema. Six out of 53 lungs $(11.3 \%)$ with mild emphysema were radiographically assessed as normal. The correct radiographic recognition of the type of emphysema was possible in $86 \%$ of lungs with mild and $97.4 \%$ with moderate centrilobular emphysema and in $81.8 \%$ and $87.5 \%$ respectively of the lungs with mild and moderate paracicatricial emphysema, but in only $25.0 \%$ and $28.6 \%$ of the lungs with mild and moderate panlobular emphysema. Radiographical diagnosis of $\frac{\circ}{\mathbb{D}}$ centrilobular and paracicatricial emphysema was verified pathologically in all lungs showing mild emphysema, but that of panlobular emphysema in only $66.7 \%$. Radiography of excised air-inflated lungs is a rapid, convenient, and reliable method of recognising and assessing the severity of appreciable degrees of centrilobular and paracicatricial emphysema, but less reliable in recognising panlobular emphysema. After the procedure the specimen remains available for almost any other technique.

Most students of lung pathology agree that the only satisfactory way of preparing the lungs at necropsy to show emphysema is to fix them in their distended state, ${ }^{1}$ and many methods of achieving this have been published. $^{2}$ These methods, however, are of little help in the detection of focal bronchiolar lesions and pulmonary vascular disease, granulomas, or small areas of fibrosis. ${ }^{3}$ We recently published a method for radiographing excised lungs during air inflation after the blood vessels have been ligated, ${ }^{4}$ and developed criteria for recognition in the radiograph of various circulatory and inflammatory disorders as well as of emphysema alone and with other lesions. ${ }^{5-8}$ After radiography the lung may be dissected fresh or fixed in any way desired. The radiograph may also help to relate the appearances of the pathological specimen to those of the patient's chest film.

This study was designed to evaluate the accuracy of

Address for reprint requests: Dr S Sutinen, Department of Pathology, Kajaanintie 52 D, SF-90220 Oulu 22, Finland. these criteria in the radiographic recognition and 3 assessment of the severity and type of pulmonary emphysema at necropsy. For this purpose two radiologists read a series of postmortem radiographs witho no prior knowledge of the corresponding pathological specimens, while two pathologistso independently examined the specimens.

\section{Methods}

The material we studied-52 right and 55 left adult lungs from 107 hospital necropsies-was completelyo different from that used previously in the develop- $\frac{}{\Phi}$ ment of diagnostic criteria ${ }^{8}$ Many of the lungs were $\stackrel{?}{+}$ from patients who had suffered from chronic airflow 0 obstruction. Lungs with intrabronchial neoplasms were excluded because of technical difficulties in air inflation and fixation. There were 72 men and 35 women in the series, their ages ranging from 33 to $999^{\circ}$ years (mean $70 \cdot 2$ years).

The technique has been described in detail. 40 Briefly, the lung was excised as intact as possible and 
the eventual pleural tears were tied or sutured. The blood vessels were ligated and the lung was radiographed in two perpendicular projections, a slow film being used in a gridless cassette exposed in a mobile condenser discharge $x$-ray unit at a focus-tofilm distance of $1 \mathrm{~m}$ during continuous intrabronchial air inflation with a pressure of $15-20 \mathrm{~cm} \mathrm{H}_{2} \mathrm{O}$. After radiography the lung was fixed intrabronchially with a solution containing polyethylene glycol, alcohol, and formalin; dried by air insufflation; and sliced sagittally into $1-\mathrm{cm}$ slices. ${ }^{9}$

The pathologists (SS, PP) classified emphysematous lesions with the naked eye into centrilobular, panlobular, and paracicatricial types,$^{10}$ and graded their severity with the help of a panel of standard photographs supplied by Thurlbeck et al. ${ }^{11}$ Centrilobular emphysema was diagnosed when lesions were unevenly distributed within the lobules and panlobular when there was an evenly coarse texture over entire lobules. ${ }^{12}$ Grade 5 was a trace amount of emphysema and grades 10-20 mild, grades 30-50 moderate, and grades 60 and over severe emphysema, the maximum severity being grade $100 .{ }^{10}$ After completion of the radiographic assessment the lungs with radiopathological discrepancies were further examined with the low-power stereomicroscope.

The radiologists (PL, RL) evaluated the severity and type of emphysema in the postmortem radiographs by using criteria already described in detail. ${ }^{8}$ These are, briefly: In mild centrilobular emphysema peripheral blood vessel densities are often reduced in amount, show irregular branching, and may be thin and broken. Small subpleural tissue defects and a few bullae may appear. In moderate centrilobular emphysema some vascular changes are always present and most lungs show unevenly distributed tissue defects, but normal-looking lung still prevails in large areas. In some lungs the shape is slightly rounded and the convexity of the diaphragm is straightened out. In severe centrilobular emphysema the number of blood vessels is greatly reduced and they are considerably dislocated, tissue defects are extensive and unevenly distributed, and the shape of the lung is always rounded and the costodiaphragmátic sinus blunted. In mild panlobular emphysema the fine reticular background is often coarser than normal, the lung is often large and may look rounded, and in some cases the number of small blood vessels is reduced. Paracicatricial emphysema appears as translucent areas around scars. There are no reliable criteria for the recognition of moderate and severe panlobular emphysema.

In addition, the radiologists used a panel of radiographs of lungs with different types and severities of emphysema containing examples of sources of errors. ${ }^{8}$ Other pathological processes were also recognised on the basis of published criteria. ${ }^{5-7}$ During the radiographic analysis each case was commented on and documented separately. Finally, the pathological and radiographic results were compared statistically.

\section{Results}

According to the pathological assessment (table 1) there were 16 lungs with no emphysema (fig 1), 38 with a trace, and 53 with at least mild emphysema.

Table 1 Correlation between pathological and radiographic assessment of the severity of emphysema in 107 lungs

\begin{tabular}{|c|c|c|c|c|c|c|c|c|c|c|c|c|c|c|c|}
\hline \multirow{3}{*}{\multicolumn{2}{|c|}{$\begin{array}{l}\text { Radiographic } \\
\text { grade }\end{array}$}} & \multicolumn{14}{|c|}{ Pathological grade } \\
\hline & & \multirow{2}{*}{$\frac{N o}{0}$} & \multirow{2}{*}{$\frac{\text { Trace }}{5}$} & \multicolumn{2}{|c|}{ Mild } & \multicolumn{3}{|c|}{ Moderate } & \multicolumn{5}{|c|}{ Severe } & \multirow[t]{2}{*}{ Total } & \\
\hline & & & & 10 & 20 & 30 & 40 & 50 & 60 & 70 & 80 & 90 & 100 & & \\
\hline Severe & $\begin{array}{l}80 \\
70 \\
60\end{array}$ & & & & & & 1 & & $\begin{array}{l}2 \\
1\end{array}$ & 3 & 1 & 2 & 1 & $\begin{array}{l}2 \\
4 \\
5\end{array}$ & 11 \\
\hline Moderate & $\begin{array}{l}50 \\
40 \\
30\end{array}$ & & & & 1 & 1 & 1 & $\begin{array}{l}2 \\
1\end{array}$ & $\begin{array}{l}1 \\
4\end{array}$ & 1 & 2 & & & $\begin{array}{l}3 \\
5 \\
6\end{array}$ & 14 \\
\hline Mild & $\begin{array}{l}20 \\
10\end{array}$ & 3 & 14 & $\begin{array}{l}1 \\
3\end{array}$ & $\begin{array}{l}4 \\
1\end{array}$ & $\begin{array}{l}1 \\
3\end{array}$ & $\begin{array}{l}5 \\
2\end{array}$ & 1 & 1 & & & & & $\begin{array}{l}11 \\
28\end{array}$ & 39 \\
\hline No & 0 & 13 & 24 & 2 & 2 & 2 & & & & & & & & 43 & \\
\hline \multirow{2}{*}{\multicolumn{2}{|c|}{ Total }} & 16 & 38 & 6 & 8 & 7 & 9 & 4 & 9 & 4 & 3 & 2 & 1 & \multirow{2}{*}{\multicolumn{2}{|c|}{107}} \\
\hline & & \multicolumn{2}{|c|}{54} & \multicolumn{2}{|c|}{14} & \multicolumn{3}{|c|}{20} & \multicolumn{5}{|c|}{19} & & \\
\hline
\end{tabular}

$r=0 \cdot 87, p<0 \cdot 0001$. 


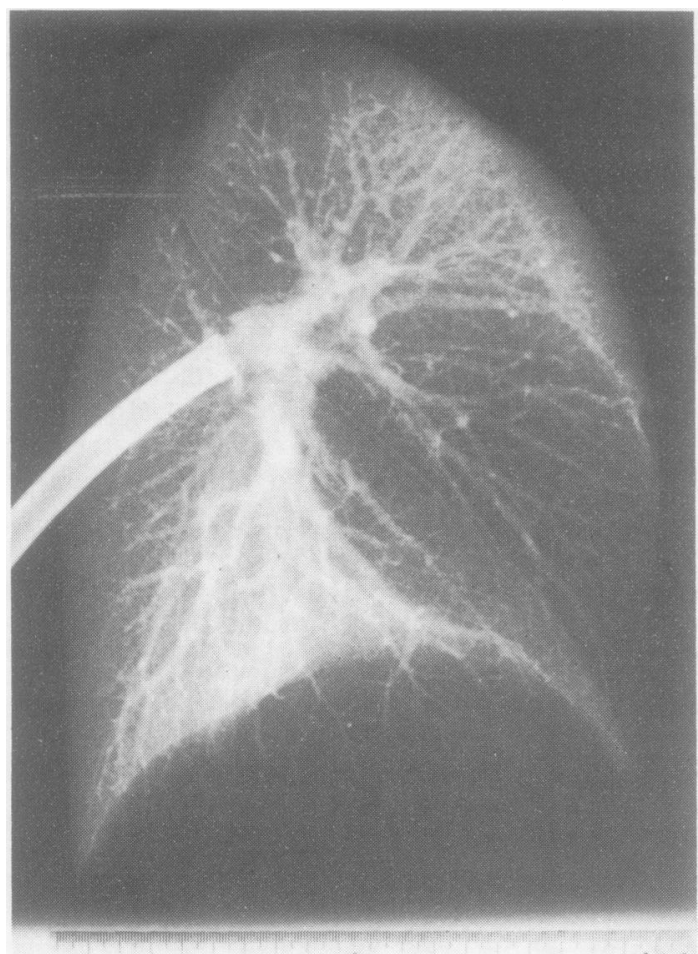

Fig 1 Lateral radiograph of an excised air-inflated normal left lung showing regularly branching blood vessels and delicate background.

The last group included 32 lungs with pure centrilobular emphysema, three with pure panlobular emphysema, seven with centrilobular emphysema and paracicatricial emphysema, and two lungs with all three types.

The correlation between pathological and radiographic assessment of the severity of emphysema is shown in table 1 . When the type of emphysema was disregarded the results of pathological and radiographic assessments of severity had a highly significant correlation $(r=0 \cdot 87, p<0 \cdot 0001)$. Emphysema that was pathologically at least mild was radiographically recognised in 47 out of 53 lungs $(88.7 \%)$, and at least moderate emphysema in 37 out of $39(94.9 \%)$. Some overlapping of mild and moderate and moderate and severe grades was observed between pathological and radiographic assessments, but only one lung with pathologically severe emphysema was radiographically assessed as being of mild grade.

Three lungs out of 16 showing no emphysema to the naked eye on pathological examination were radiographically assessed as showing mild emphysema. When these lungs, however, were later re- examined using also the stereomicroscope, two of them showed minute foci of centrilobular emphysema and paracicatricial emphysema in the apical region, as did the radiographs. This left only one false-positive radiographic assessment $(6 \cdot 3 \%)$. Six lungs out of $53(11.3 \%)$ showing at least mild emphysema pathologically were radiographically assessed as non-emphysematous $(11.3 \%)$. In one of these false-negative cases the lung had not been adequately filled with air at radiography. In another mild emphysema occurred in a grossly polycystic lung and in a third it was associated with metastatic cancer. In three cases no explanation for the erroneous assessment could be found.

Table 2 shows the results of radiographic assessment of the type of emphysema in the lungs assessed pathologically as having at least mild emphysema. Centrilobular emphysema (figs 2-4) and paracicatricial emphysema (fig 5), occurring alone or in combination with other types, were recognised in the radiographs in $86 \%$ and $81.8 \%$ of the lungs, but the panlobular type (fig 6) in only $25 \%$.

In the lungs assessed pathologically as showing at least moderate emphysema (table 3 ) centrilobular emphysema alone or in combination with other types was radiographically recognised in practically all cases $(97 \cdot 4 \%)$. The same held true for paracicatricial emphysema $(87.5 \%)$, whereas panlobular emphysema was recognised in less than a third of the lungs $(28 \cdot 6 \%)$.

The results of pathological verification of radiographic classification of emphysema in 53 lungs with at least mild emphysema are shown in table 4 . When centrilobular emphysema, alone or in com-

Table 2 Radiographical recognition of type of emphysema in 53 lungs assessed pathologically as being of at least mild grade (some lungs showing more than one type)

\begin{tabular}{lll}
\hline $\begin{array}{l}\text { Type of } \\
\text { emphysema }\end{array}$ & $\begin{array}{l}\text { No in which } \\
\text { present }\end{array}$ & $\begin{array}{l}\text { No (\%) in which } \\
\text { recognised } \\
\text { radiographically }\end{array}$ \\
\hline Centrilobular & 50 & $43(86 \cdot 0)$ \\
Paracicatricial & 11 & $9(81 \cdot 8)$ \\
Panlobular & 12 & $3(25 \cdot 0)$ \\
\hline
\end{tabular}

Table 3 Radiographical recognition of the type of emphysema in 39 lungs assessed pathologically as being of at least moderate grade (some lungs showing more than one type)

\begin{tabular}{lll}
\hline $\begin{array}{l}\text { Type of } \\
\text { emphysema }\end{array}$ & $\begin{array}{l}\text { No in which } \\
\text { present }\end{array}$ & $\begin{array}{l}\text { No (\%) in which } \\
\text { recognised } \\
\text { radiographically }\end{array}$ \\
\hline Centrilobular & 38 & $37(97.4)$ \\
Paracicatricial & 8 & $7(87.5)$ \\
Panlobular & 7 & $2(28.6)$ \\
\hline
\end{tabular}




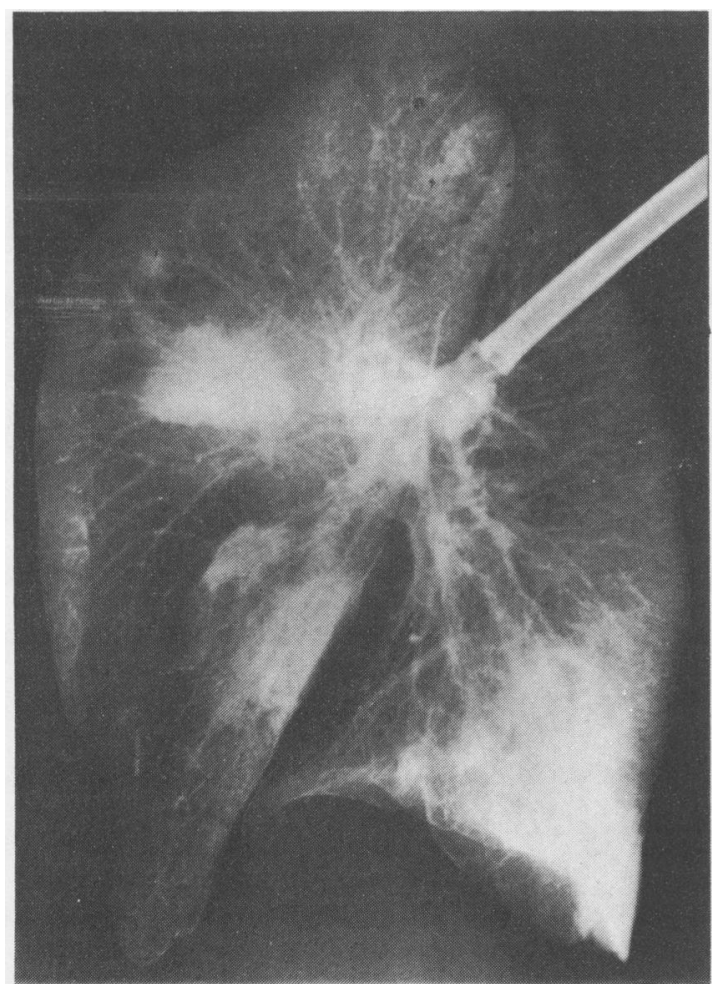

Fig 2 Lateral radiograph of left lung showing mild centrilobular emphysema (grade 20 both pathologically and radiographically): there is reduction in the number of peripheral blood vessels in the apicoposterior and anterior segments of the upper lobe and tissue defects in the apex, with multiple infarcts in other parts of the lung.

bination with other types, was seen radiographically the finding was verified pathologically in all 47 lungs. Paracicatricial emphysema was seen radiographically in considerably more lungs than those in which it was pathologically verified in the initial examination. On re-examination, however, the finding was pathologically verified in all 17 lungs. Thus radiography proved more accurate than pathological examination by the naked eye for recognising minute scars and minimal paracicatricial emphysema. The radiographic diagnosis of panlobular emphysema made in six lungs was pathologically verified in only four of them. The proportion of pathologically verified radiographic diagnoses of panlobular emphysema was essentially the same as for paracicatricial emphysema in lungs with at least moderate emphysema.

\section{Discussion}

In examining the lung at necropsy the pathologist usually has to decide what kind of information is

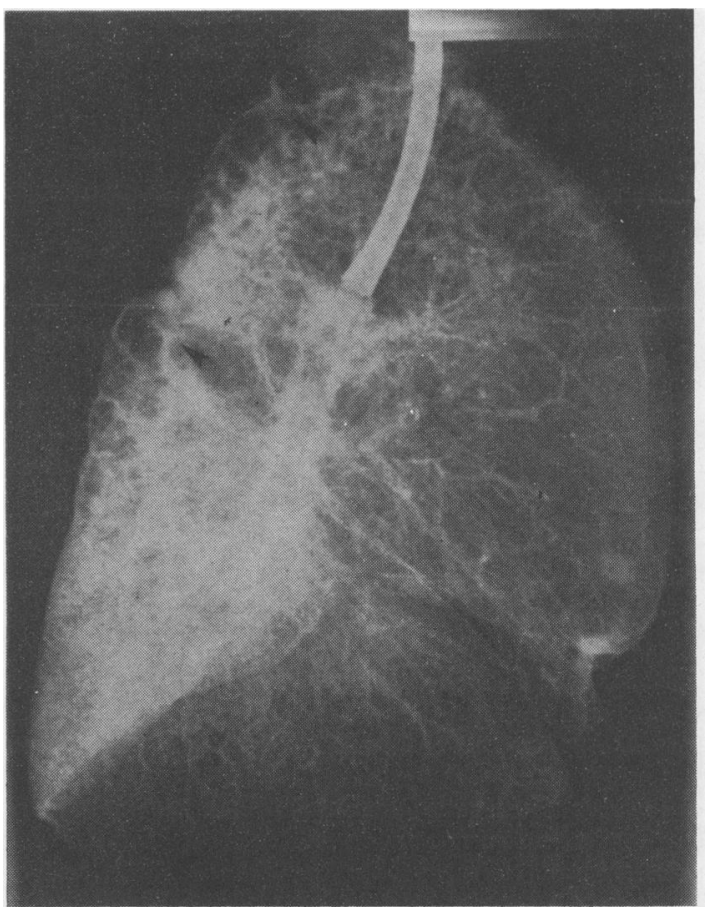

Fig 3 Lateral radiograph of left lung showing moderate centrilobular emphysema (grade 50 both pathologically and radiographically): there is rounding of the anterior margin and disappearance of the diaphragm's convexity; blood vessels are generally reduced; tissue defects are evident in the posterior parts of the lung; and two scars (arrows), with abundant alveolar oedema and some interstitial oedema posteriorly.

needed in any individual case before dissecting or fixing the organ, since many techniques preclude the use of others. ${ }^{13}$ Necessary information may be lost if the need for it is recognised too late. Radiographing the excised air-inflated lung after the blood vessels have been ligated leaves most of the organ intact, and the decision to dissect or fix may be made after the interpretation of the radiograph, by which many

Table 4 Pathological verification of radiographical classification of emphysema in 53 lungs assessed pathologically as being of at least mild grade (some lungs showing more than one type)

\begin{tabular}{|c|c|c|c|}
\hline \multirow[t]{2}{*}{$\begin{array}{l}\text { Type of } \\
\text { emphysema }\end{array}$} & \multirow{2}{*}{$\begin{array}{l}\text { No in which } \\
\text { radiographically } \\
\text { present }\end{array}$} & \multicolumn{2}{|c|}{$\begin{array}{l}\text { No (\%) in which pathologically } \\
\text { verified }\end{array}$} \\
\hline & & $\begin{array}{l}\text { Initial } \\
\text { examination }\end{array}$ & Re-examination \\
\hline $\begin{array}{l}\text { Centrilobular } \\
\text { Paracicatricial } \\
\text { Panlobular }\end{array}$ & $\begin{array}{r}47 \\
17 \\
6\end{array}$ & $\begin{array}{rr}47 & (100 \cdot 0) \\
8 \\
3\end{array} \quad\left(\begin{array}{c}47 \cdot 1 \\
50 \cdot 0)\end{array}\right.$ & $\begin{array}{r}17(100 \cdot 0) \\
4(66 \cdot 7)\end{array}$ \\
\hline
\end{tabular}




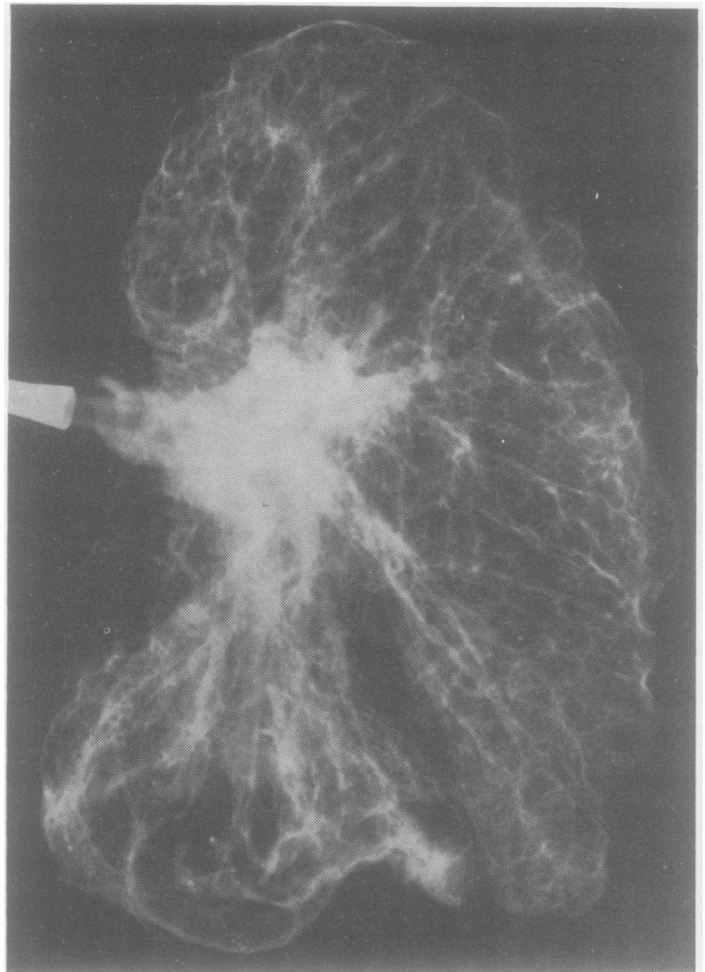

Fig 4

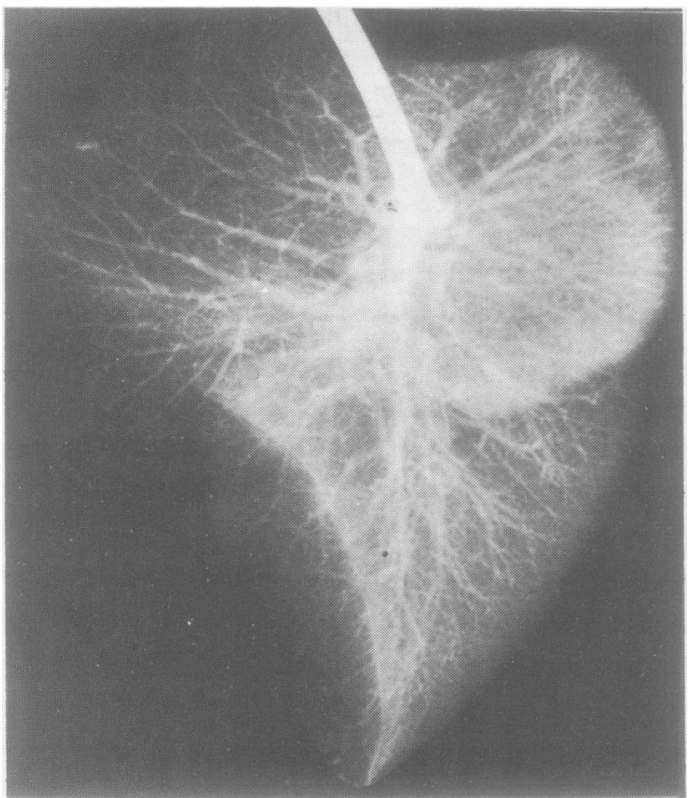

Fig 6

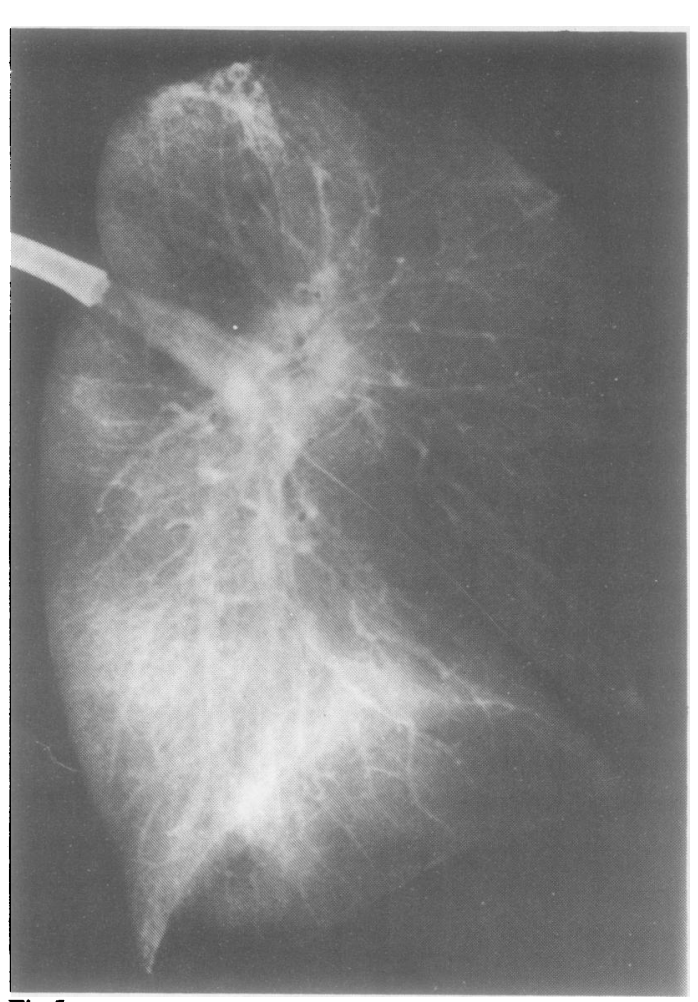

Fig 5

Fig 4 Lateral radiograph of left lung showing severe centrilobular emphysema (grade 80 both pathologically and radiographically): the shape is rounded, blood vessel densities are greatly reduced, and tissue defects are extensive.

Fig 5 Lateral radiograph of left lung showing apical scar with surrounding mild paracicatricial emphysema (grade 5 pathologically and grade 10 radiographically): alveolar oedema is present in posterior parts of the lung.

Fig 6 Lateral radiograph of right lung showing a trace amount of panlobular emphysema (grade 5 pathologically and grade 10 radiographically): there is bulging of anterior parts of the upper lobe indicating reduction in elastic properties, with slight alveolar oedema in posterior parts of the upper lobe. 
lesions may be recognised, excluded, or suspected..$^{5-8}$ The shortest time needed to get a reliable estimate of emphysema by inflation fixation is one hour before the lung is sliced but for permanent specimens at least 24-hour fixation is required..$^{13} \mathrm{~A}$ radiograph of the excised lung may be produced in 10-15 minutes, and with some experience the presence or absence of appreciable emphysema may be assessed in a few minutes-a closer analysis of the radiograph taking an additional 5-10 minutes.

Postmortem bronchography has been used in the study of emphysema, ${ }^{14}$ and several correlative radiological and pathological studies have been published on the appearance and accuracy of evaluation of emphysema on the chest radiograph; $;^{15-18}$ but we are not aware of any previous investigation of the accuracy of the radiographic assessment of emphysema at necropsy.

In cases judged pathologically as having severe emphysema Thurlbeck and Simon were able to recognise emphysema in $41 \%$ of the corresponding chest radiographs taken during life. ${ }^{18}$ As might be expected, the exclusion of the chest wall and mediastinum and the use of a slow-film technique with high resolution, as in our study, considerably increases the accuracy of the radiographic assessment. We found good agreement between pathological and radiographic assessments of severity of emphysema. The detection rate was high and the false-positive rate low. Although centrilobular and paracicatricial emphysema were reliably recognised radiologically even when mild, the detection rate of panlobular emphysema was poor and the false-positive rate high; no cases of severe panlobular emphysema were studied, however. Hasleton ${ }^{19}$ observed that cases of alveolar duct (that is, panlobular) emphysema are both overdiagnosed and underdiagnosed on macroscopic point counting of the pathological specimen and that reliable recognition is possible only by using quantitative histological methods, such as the determination of the mean linear intercept. The accuracy of the method of macroscopic quantitation of emphysema used by us is comparable to macroscopic point counting. ${ }^{11}$ Thus more sophisticated quantitative study of the pathological specimen would probably be needed in the development of new criteria for recognising and grading panlobular emphysema in the radiograph.

In conclusion, radiography of the excised airinflated lung is a rapid, convenient, and (at least in our hands) very reliable method for recognising, classifying, and assessing the severity of significant centrilobular emphysema and paracicatricial emphysema at necropsy; while the recognition of panlobular emphysema awaits further development of reliable criteria.
We are grateful to Professor Pekka Vuoria for help with the manuscript, Mr Tapio Leinonen and Mrs Liisa Kärki for technical assistance, and the Sigrid Juselius Foundation and Finnish Antituberculosis Association for financial support.

\section{References}

${ }^{1}$ Heard BE. Pathology of chronic bronchitis and emphysema. London: J and A Churchill, 1969.

${ }^{2}$ Ludwig J. Current methods of autopsy practice. 2nd ed. Philadelphia: Saunders, 1979.

${ }^{3}$ Dunnill MS. Radiology as an adjunct to pathology in elucidation of pulmonary disease at necropsy. Eur $J$ Respir Dis 1981;62:287-8.

${ }^{4}$ Sutinen S, Pääkkö P, Lahti R. Post-mortem inflation, radiography, and fixation of human lungs. A method for radiological and pathological correlations and morphometric studies. Scand J Respir Dis 1979;60:2935.

${ }^{5}$ Pääkkö $P$, Sutinen S, Lahti R. Pattern recognition in radiographs of excised air-inflated human lungs. ICirculatory disorders in non-emphysematous lungs. Eur J Respir Dis 1981;62:21-32.

${ }^{6}$ Pääkkö P, Sutinen S, Lahti R. Pattern recognition in radiographs of excised air-inflated human lungs. IIAcute inflammation in non-emphysematous lungs. Eur J Respir Dis 1981;62:33-45.

${ }^{7}$ Pääkkö P. Pattern recognition in radiographs of excised air-inflated human lungs. III-Chronic inflammation, fibrosis and lymphangitis carcinomatosa in nonemphysematous lungs. Eur J Respir Dis 1981;62:28996.

${ }^{8}$ Sutinen S, Pääkkö P, Lohela P, Lahti R. Pattern recognition in radiographs of excised air-inflated human lungs. IV-Emphysema alone and with other common lesions. Eur J Respir Dis 1981;62:297-314.

${ }^{9}$ Markarian B. A simple method of inflation-fixation and air drying of lungs. Am J Clin Pathol 1975;63:20-4.

${ }^{10}$ Sutinen S, Vaajalahti P, Pääkkö P. Prevalence, severity, and types of pulmonary emphysema in a population of deaths in a Finnish city. Correlation with age, sex and smoking. Scand J Respir Dis 1978;59:101-15.

${ }^{11}$ Thurlbeck WM, Dunnill MS, Hartung W, Heard BE, Heppleston AG, Ryder RC. A comparison of three methods of measuring emphysema. Hum Pathol 1970;1:215-26.

${ }^{12}$ Pratt PC, Kilburn KH. A modern concept of the emphysemas based on correlations of structure and function. Hum Pathol 1970;1:443-63.

${ }^{13}$ Whimster WF. Techniques for the examination of excised lungs. Hum Pathol 1970;1:305-14.

${ }^{14}$ Leopold JG, Gough J. Post-mortem bronchography in the study of bronchitis and emphysema. Thorax 1963; 18:172-7.

${ }^{15}$ Laws JW, Heard BE. Emphysema and chest film. A retrospective radiological and pathological study. $\mathrm{Br} J$ Radiol 1962;35:750-61.

${ }^{16}$ Sutinen S, Christoforidis AJ, Pratt PC, Klugh GA. Roentgenologic criteria for the recognition of nonsymptomatic pulmonary emphysema. Correlation 
between roentgenologic findings and pulmonary pathology. Am Rev Respir Dis 1965;91:69-76.

${ }^{17}$ Nicklaus TM, Stowell DW, Christiansen WR, Renzetti $\mathrm{AD}$. The accuracy of the roentgenologic diagnosis of chronic pulmonary emphysema. Am Rev Respir Dis 1966;93:889-99.
${ }^{18}$ Thurlbeck WM, Simon G. Radiographic appearance of the chest in emphysema. Am J Roentgenol 1978;130:429-40.

${ }^{19}$ Hasleton PS. The internal surface area of the lung in emphysema. Pathol Eur 1976;11:211-8. 